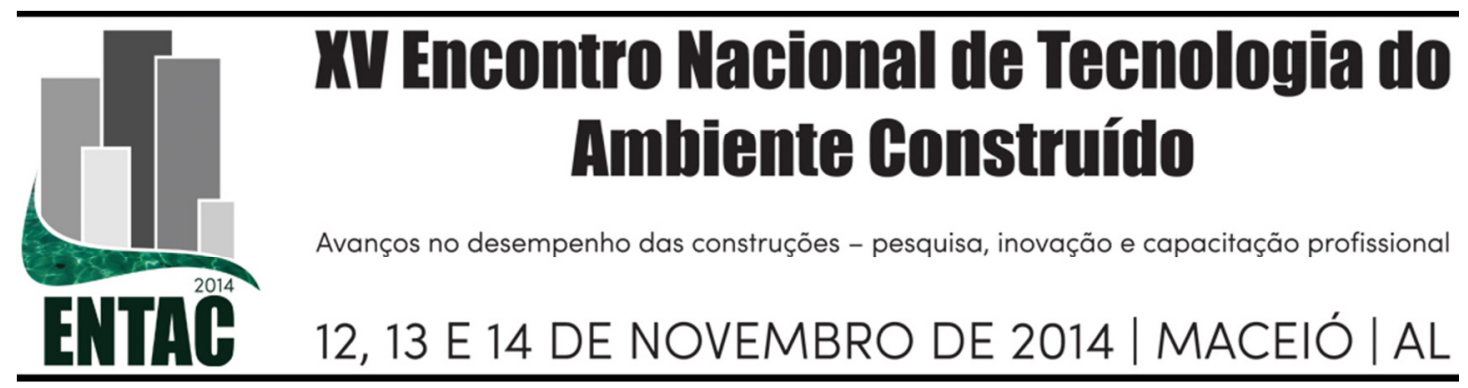

\title{
ENSAIO ESTÁTICO E DINÂMICO DE PROTEÇÕES COLETIVAS CONTRA QUEDAS DE ALTURA EM CANTEIROS DE OBRAS
}

\author{
COSTELlA, Marcelo Fabiano (1); PILZ, Silvio Edmundo (2); SORGATO, Pedro \\ Luciano (3); BALDISSERA, Ademir (4)
}

(1) UNOCHAPECO e IMED, costella@ unochapeco.edu.br, (2) UNOCHAPECO, silvio@unochapeco.edu.br, (3) UNOCHAPECO, pedrols@unochapeco.edu.br,

(4)UNOCHAPECO,engenharia.adm@unochapeco.edu.br.

\begin{abstract}
RESUMO
A segurança do trabalho em um canteiro de obras no que diz respeito à proteção contra queda de alturas é constituída, na maioria das vezes, por um equipamento de proteção coletiva denominado guarda-corpo e rodapé $(\mathrm{GcR})$. Existem várias maneiras de construí-lo, o que leva a desempenhos distintos em termos de prevenção de acidentes. O objetivo deste artigo é realizar ensaios de resistência estático e dinâmico nos sistemas de GcR tendo como base a NR18 e a norma NBR 14.718 (2001) que determina os padrões para guarda-corpos definitivos. Este artigo é o resultado de um projeto de pesquisa que busca avaliar a qualidade das proteções coletivas em canteiros de obras. Esta pesquisa experimental iniciou por meio do desenvolvimento de um equipamento para realização de ensaios dinâmicos e estáticos, visto que os equipamentos até então disponíveis não permitiam o teste das variadas condições em que se situam os GcR nas obras. Após a validação do equipamento, foram testados oito tipos diferentes de GcR. Foram testadas três situações distintas tendo em vista que a NR18 não especifica com clareza as condições, por isso foram utilizados os critérios da NBR 14.718, os quais são mais claros, porém mais exigentes. Dentre os resultados, após a avaliação dos materiais utilizados na confecção, método de fixação e vão livre do sistema de GcR pode-se observar que, no teste estático, apenas $25 \%$ dos GcR testados resistiram ao esforço estático de $80 \mathrm{~kg}$ e nenhum resistiu ao esforço estático de $150 \mathrm{~kg}$, preconizado pela NR18. No ensaio dinâmico, 75\% dos GcR resistiram ao impacto de $700 \mathrm{~J}$, entretanto um dos conjuntos rompeu, ou seja, não teria atendido a sua função de amparar o trabalhador.
\end{abstract}

Palavras-chave: Segurança no Trabalho, desempenho, Guarda-Corpo com Rodapé, GcR

\begin{abstract}
Work safety in a construction site concerning the protection against falling from heights consists, most of the times, by a collective protection equipment called body guard and baseboard (GwF). There are several ways to build it, which leads to distinct results in terms of accident prevention performance. The purpose of this article is to do tests of static and dynamic resistance in GwF systems based on the NR18 and NBR 14.718 (2001), which determines the standards for definitive body guard. This article is the result of a research project that aims to assess the quality of the collective protection on construction sites. This experimental research began through the development of a device for performing dynamic and static tests, since the equipment available so far did not allow testing of the varied conditions where the $G w F$ are situated in the construction sites. After the validation of the test equipment, eight different types of GwF were tested. Three different situations were tested considering that the NR18 does not specify clearly the conditions, so the criteria of NBR 14.718, were used because they are best defined, but more demanding. Among the results, after the materials evaluation used in the manufacture, fixing method and clearence of the GwF system, it is possible to observe observed that, in the static test, only $25 \%$ of GwF tested resisted to the static force of $80 \mathrm{~kg}$ and none resisted to the static force of $150 \mathrm{~kg}$, recommended by NR18. In the dynamic test, $75 \%$ of GwF resisted the impact of $700 \mathrm{~J}$, however one of the sets has broken, in other words, they would not have served its function of supporting workers.
\end{abstract}


Keywords: Safety at Work, Performance, Body Guard with Baseboard, GwF.

\section{INTRODUÇÃO}

A construção civil é um grande responsável pela geração de empregos no país devido ao fato da mão-de-obra ser geralmente não especializada, bem como, a qualificação ser muito baixa. Segundo o Ministério da Previdência (BRASIL, 2012), cerca de $700 \mathrm{mil}$ casos de acidentes de trabalho são registrados em média no Brasil todos os anos, sem contar os casos não notificados oficialmente.

Os trabalhos em altura são considerados pelo MTE o maior causador de acidentes nos últimos anos no cenário industrial brasileiro e um dos principais motivos é a falta de treinamento e educação profissional dos trabalhadores (BRASIL, 2012).

Nesse contexto, se torna muito importante a fiscalização por parte não só dos órgãos fiscais, mas também dos próprios empregadores e empregados. A partir do momento que todos fazem a sua parte o nível de segurança cresce continuamente.

As proteções coletivas devem ser utilizadas como medidas para evitar as quedas dos trabalhadores, além de ser uma exigência da NR 18 (item 18.13.4).

Um ponto preocupante é a visível falta de comprometimento das empresas para com a montagem dos sistemas de guarda-corpo e rodapé (GcR). Algumas empresas montam os sistemas sem respeitar os requisitos mínimos estabelecidos pela NR 18 e em alguns casos não há esse tipo de proteção para os trabalhadores, colocando em risco a saúde de todos. A avaliação desses sistemas poderá mostrar se as normas estão sendo cumpridas e se mesmo seguindo a norma as proteções coletivas garantem a segurança dos trabalhadores em diferença de nível.

\section{SEGURANÇA NO TRABALHO NA CONSTRUÇÃO CIVIL}

\subsection{Equipamentos de Proteção Coletiva - EPC's}

Segundo a NR-9 (BRASIL, 2011), os equipamentos de proteção coletiva (EPC) têm a finalidade de eliminar e/ou diminuir os riscos de acidentes ou doenças ocupacionais, como por exemplo: guarda-corpos, proteções de aberturas no piso, escoramento de valas, plataformas de proteção, etc. Sampaio (1998) considera qualquer ação, equipamento que serve de barreira entre o perigo e os operários. Conforme a NR-18 (BRASIL, 2013), o projeto de execução e implantação das proteções coletivas deve fazer parte dos documentos que integram o PCMAT, além dos mesmos terem que ser projetados e dimensionados por profissional legalmente habilitado. Segundo Fundacentro (2005), o sistema de guarda-corpo e rodapé destina-se a promover a proteção contra riscos de queda de pessoas, matérias ou ferramentas sendo que tal sistema deve ser constituído por uma proteção de material rígido e resistente, fixada e instalada nos pontos onde haja risco de queda de pessoas e matérias.

A NR 18 no item 18.13.5 que trata sobre anteparos rígidos para proteção de queda de trabalhadores e projeção de material, quanto Fundacentro (2005), estabelecem a mesma altura para travessões e a altura do rodapé. Sendo para o travessão superior altura de $1,20 \mathrm{~m}$ (um metro e vinte $\mathrm{cm}$ ), para o travessão intermediário $0,70 \mathrm{~m}$ (setenta $\mathrm{cm}$ ), possuir rodapé com altura de $0,20 \mathrm{~m}$ (vinte $\mathrm{cm}$ ), e ter os vãos entre travessas preenchidos com tela ou outro dispositivo que garanta o fechamento seguro da abertura, conforme figura 1 . 


\section{Figura 1 - Sistema Guarda - corpo - Rodapé (GcR)}

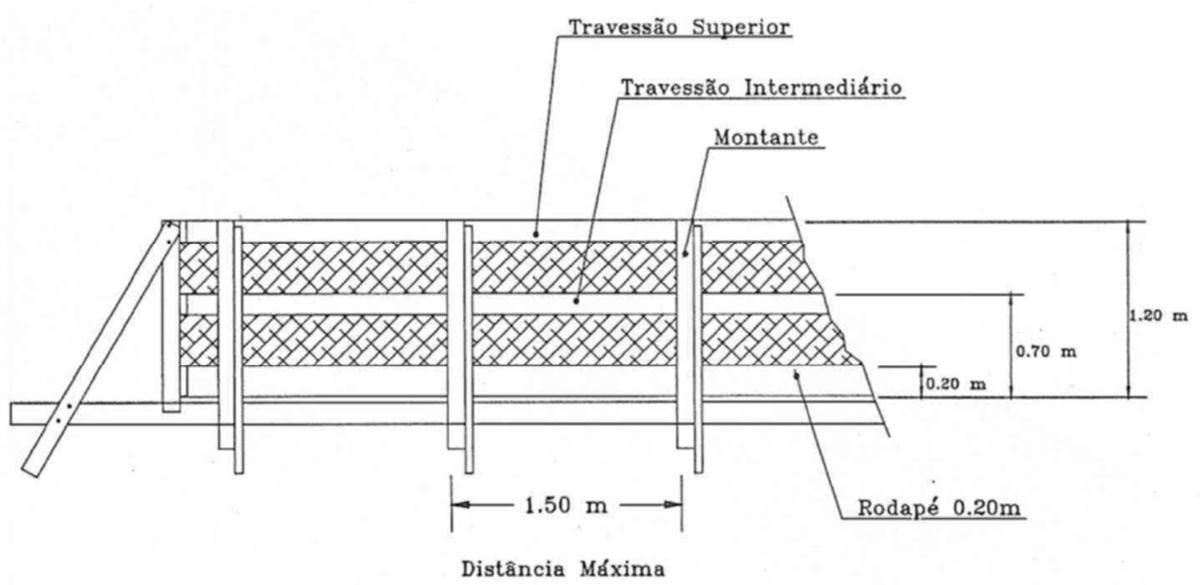

Fonte: Fundacentro (2005)

\subsection{Ensaios estáticos}

Segundo a NBR 14.718 (2001), para o ensaio de esforço estático horizontais em qualquer tipo ou modelo de guarda-corpo, quando submetido ao ensaio deve atender aos requisitos indicados: a) não deve apresentar ruptura de qualquer de seus componentes; b) não deve ocorrer afrouxamento ou destacamento de componentes e dos elementos de fixação; c) a deformação sob carga (deslocamento do peitoril) não deve superar L/250, sendo L o vão considerado para ensaio; d) a deformação residual deve ser limitada a L/1000 ou $3 \mathrm{~mm}$, sendo L o vão considerado para ensaio.

Quanto à aplicação dos esforços a NBR 14.718 (2001), cita que devem ser aplicados em pontos equidistantes não superiores a um metro. Caso o guarda-corpo tiver o comprimento inferior a um metro, para este o esforço deve ser aplicado em seu centro. O mesmo deve ser considerado na presença de montantes intermediário com ou sem função estrutural, onde os esforços devem ser distribuídos equidistantes entre si.

O ensaio estático (horizontal) consiste na aplicação de um carregamento por um determinado tempo sobre o guarda-corpo. A NR 18 não estabelece valores para o carregamento. Por outro lado, a RTP 01 (FUNDACENTRO, 2005) estabelece um valor de $150 \mathrm{~kg} / \mathrm{m}$, e a NBR 6120 (1980) estabelece $80 \mathrm{~kg} / \mathrm{m}$. A NBR 14718 (2001) determina que deva ser instalado relógio comparador para a leitura das deformações, as quais devem ser feitas após 15 minutos da atuação da carga e após 5 minutos do alívio da carga, para verificação da deformação residual.

\subsection{Ensaios dinâmicos}

Segundo a NBR 14.718 (2001), para o ensaio de esforço estático dinâmico em qualquer tipo ou modelo de guarda-corpo, quando submetido ao ensaio deve atender aos requisitos indicados: a) Não deve ocorrer ruptura ou destacamento das fixações; b) Não deve ocorrer queda do painel ou de perfis, no caso de guarda-corpos do tipo gradil; c) A ruptura de qualquer componente não deve implicar risco de queda do agente causador do impacto. Sendo somente tolerado: a) Afrouxamento de fixações; b) Deformações nos perfis constituintes do guarda-corpo e no peitoril, inclusive; c) Ruptura do painel, desde que o mesmo permaneça no guarda-corpo. A NBR 14.718 (2001) descreve um modelo para aplicação do impacto sobre os sistemas de guarda-corpo e rodapé, conforme figura 2. O ensaio dinâmico segundo a NBR 14.718 (2001) consiste na aplicação de um 
impacto de $700 \mathrm{~J}$, aplicado no centro geométrico do painel, com tolerância máxima de $50 \mathrm{~mm}$, formado ao redor do centro de gravidade do sistema de guarda-corpo.

Figura 2 - Modelo de aplicação do impacto sobre painéis de guarda - corpos

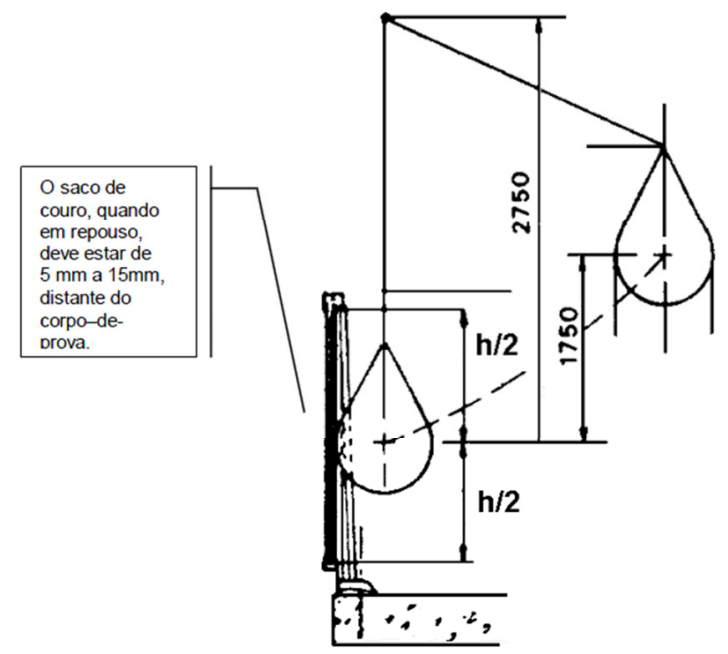

Fonte: NBR 14.718 (ABNT, 2001)

\section{PROCEDIMENTOS METODOLÓGICOS}

\subsection{Seleções das obras e dos guarda-corpos para ensaio}

Os ensaios de sistemas de guarda-corpo e rodapé, tanto estáticos quanto dinâmico foram realizados em cinco obras da cidade de Chapecó. Na empresa "A" foram realizados os ensaios 1,2 e 3. Na empresa "B" apenas foi realizado o ensaio o ensaio 4. Na empresa "C" foram realizados os ensaios 5 e 6 . Na empresa " $D$ " foi realizado o ensaio o ensaio 7 e por final foi realizado o ensaio o ensaio 8 na empresa " $E$ ".

Não houve um critério específico para a escolha das empresas para realização dos ensaios de guarda-corpo com rodapé. As empresas foram selecionadas devido a diversidade de GcR, e por permitirem o acesso à obra e realização dos ensaios.

\subsection{Equipamento e material para ensaio}

Para ensaiar o sistema de guarda-corpo e rodapé, foi necessária a criação de um equipamento para transferir o esforço conforme o que prediz as normas. Para isso foram utilizados perfis metálicos de $40 \times 40 \mathrm{~mm}$ e $50 \times 50 \mathrm{~mm}$ com espessura de $2 \mathrm{~mm}$, que foram soldados (solda MIG) e parafusados.

Durante a elaboração do equipamento, foi levado em conta a diversidade de onde o mesmo seria instalado e a força que o mesmo deveria suportar, esse é um dos motivos por o mesmo ser praticamente desmontável e telescópico, conforme figura 05.

Para a realização do teste estático foi utilizado o equipamento montado conforme a figura 3. Utilizando sistema de contrapeso e roldanas fixas, foi possível realizar a aplicação de tração no guarda-corpo no sentido externo a edificação. Na elaboração do ensaio se utilizou roldanas de duas polegadas e meia (21/2") para não ter perda de atrito e cabo de aço de cinquenta milím (3/16") para não haver perda com a deformação térmica. Para contrapeso foram utilizados cem quilogramas $(100 \mathrm{~kg})$ de chumbo e cinquenta quilogramas $(50 \mathrm{~kg})$ de areia. 
Figura 3 - Montagem do equipamento para teste estático

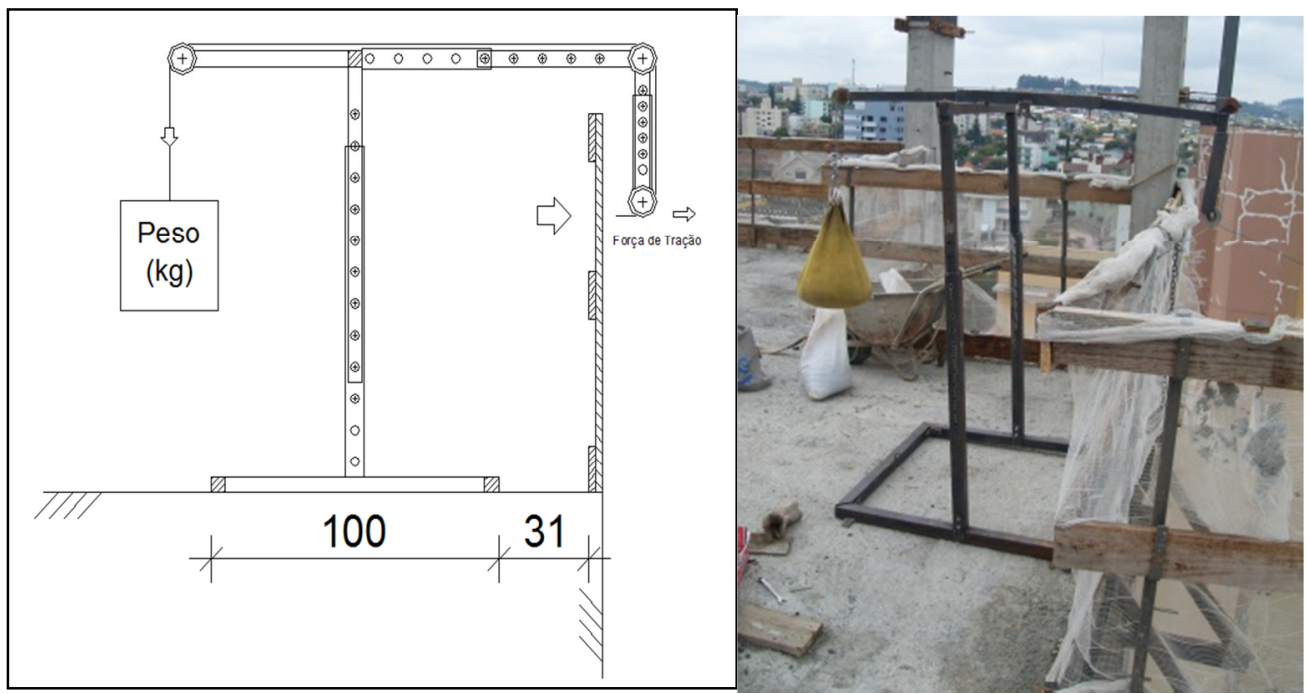

Fonte: elaboração dos autores

Para o ensaio dinâmico, foi utilizado o mesmo cabo de aço do ensaio estático. Foi utilizado um saco em couro com capacidade de cem quilogramas de chumbo em pó para a realização do ensaio de corpo mole. O chumbo foi dividido em pequenos pacotes para facilitar o transporte e montagem do ensaio. $O$ equipamento foi montado conforme a figura 4, para o ensaio dinâmico.

Figura 4 - Montagem do equipamento para teste dinâmico
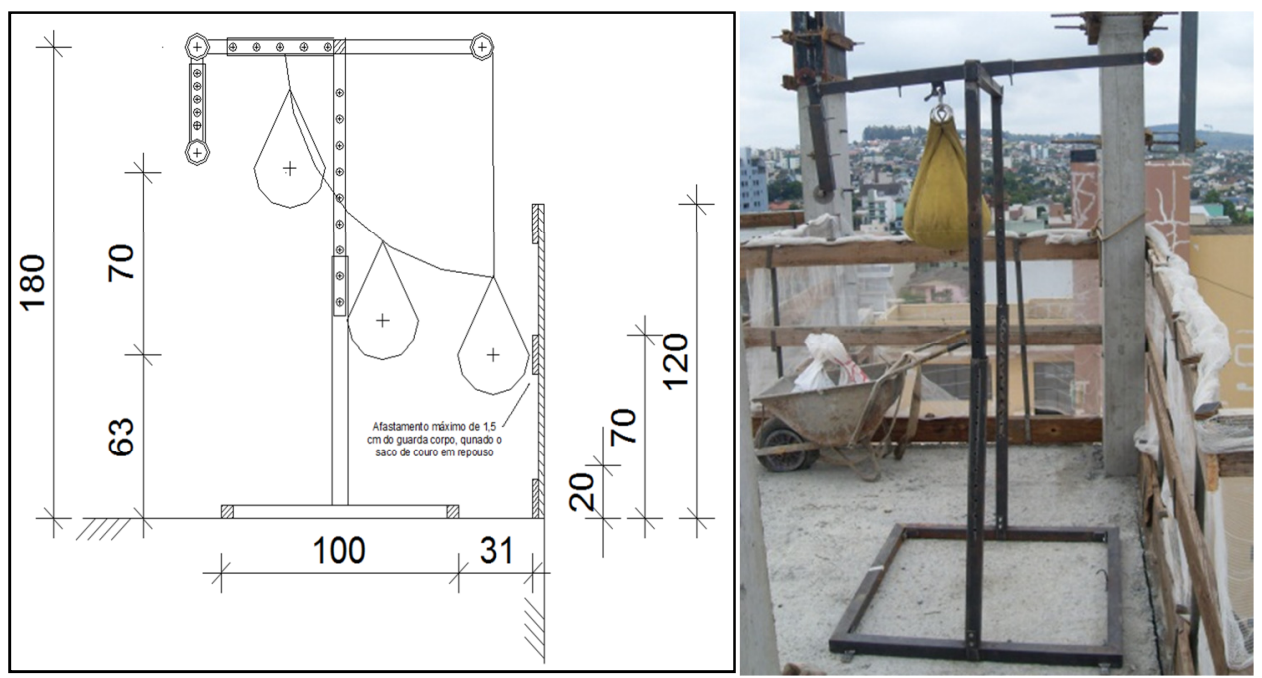

Fonte: elaboração dos autores

\section{RESULTADOS}

\subsection{Descrição dos guardas corpos com rodapé ensaiados}

\subsubsection{Ensaio 01}

Guarda-corpo composto por guias em madeira $(2,5 \mathrm{~cm}$ de espessura) e comprimento de total de 5,10 m, contendo montantes de escoras de madeira bruta com espaçamento de $1,70 \mathrm{~m}$ entre elas e tela de proteção. As guias que compõem o guarda-corpo e o rodapé 
são pregadas nas escoras que, por sua vez, são calçadas na estrutura de concreto armado, na periferia do prédio, conforme figura 5.

\subsubsection{Ensaio 02}

Guarda-corpo composto por guias em madeira e comprimento de total de 4,80 m, contendo montantes de escoras de madeira de $2,5 \mathrm{~cm}$ em forma de mão francesa com espaçamento de 2,40 m entre elas. Situado no acesso a uma sacada de apartamento.

\subsubsection{Ensaio 03}

Guarda-corpo composto por guias em madeira e comprimento de total de $4,80 \mathrm{~m}$, sem montantes e com tela de proteção. Situado na periferia da edificação, onde posteriormente será realizado o acabamento apenas com painéis de vidro.

\subsubsection{Ensaio 04}

Guarda-corpo com guias em madeira e comprimento de total de 3,70 m, com montantes metálicos fixados através de encaixe sobre vigas e utilizado sistema de parafuso para fixação através de pressão, e com tela de proteção, conforme figura 6.

Figura 5 - Ensaio 01

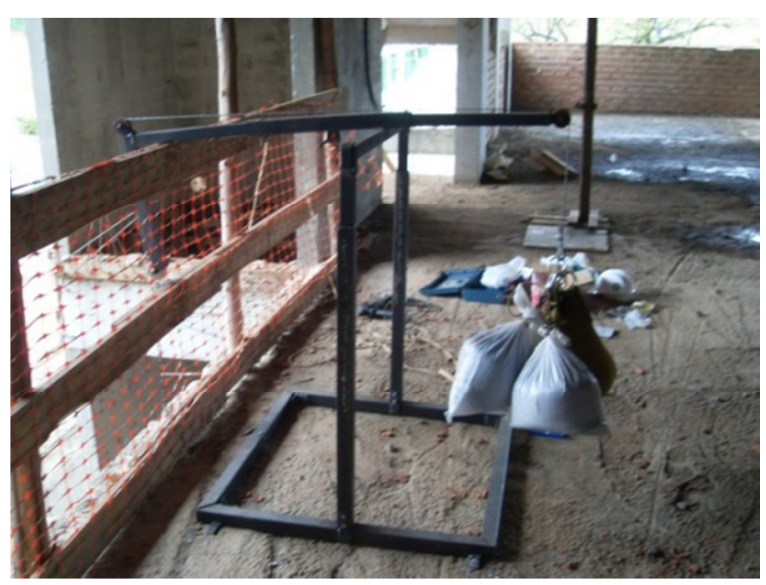

Fonte: elaboração dos autores
Figura 6 - Ensaio 04

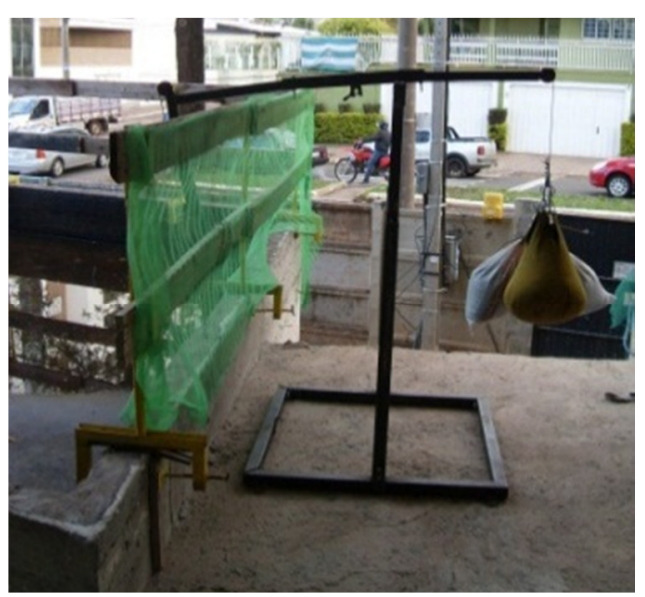

Fonte: elaboração dos autores

\subsubsection{Ensaio 05}

Guarda-corpo com guias em madeira e comprimento de total de 1,70 m, com montantes em barrotes de madeira de 2,5 x 2,5 cm fixados com agulhas nas vigas, situado no poço do elevador da edificação, e com tela de proteção.

\subsubsection{Ensaio 06}

Guarda-corpo de periferia de laje, com guias em madeira e comprimento de total de 3,80 m, com montantes metálicos, encaixados nas formas das vigas e com tela de proteção, conforme figura 7 .

\subsubsection{Ensaio 07}

Guarda-corpo em abertura de acesso a sacada, constituído por travessões de $2,5 \mathrm{~cm}$ de espessura com comprimento de $2,00 \mathrm{~m}$ sem montantes e sem tela de proteção, simplesmente encaixado em suportes de madeira fixados na alvenaria (figura 8). 
Figura 7 - Ensaio 06

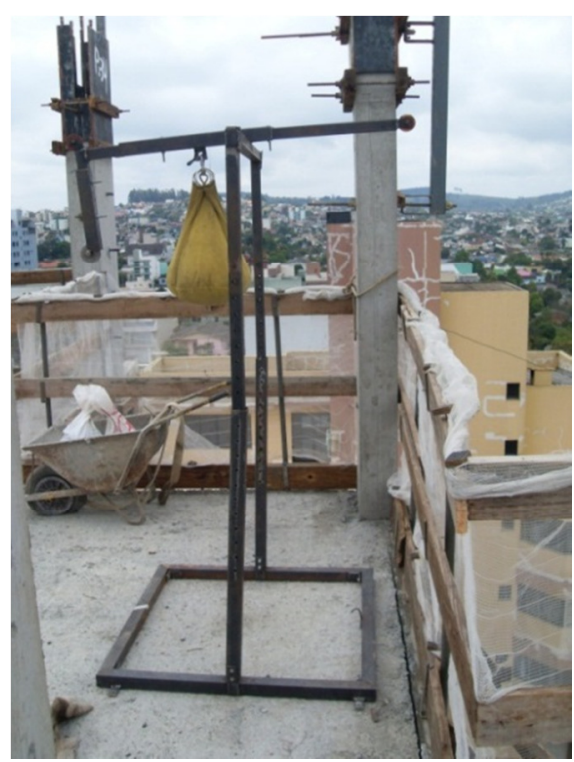

Fonte: elaboração dos autores
Figura 8 - Ensaio 07

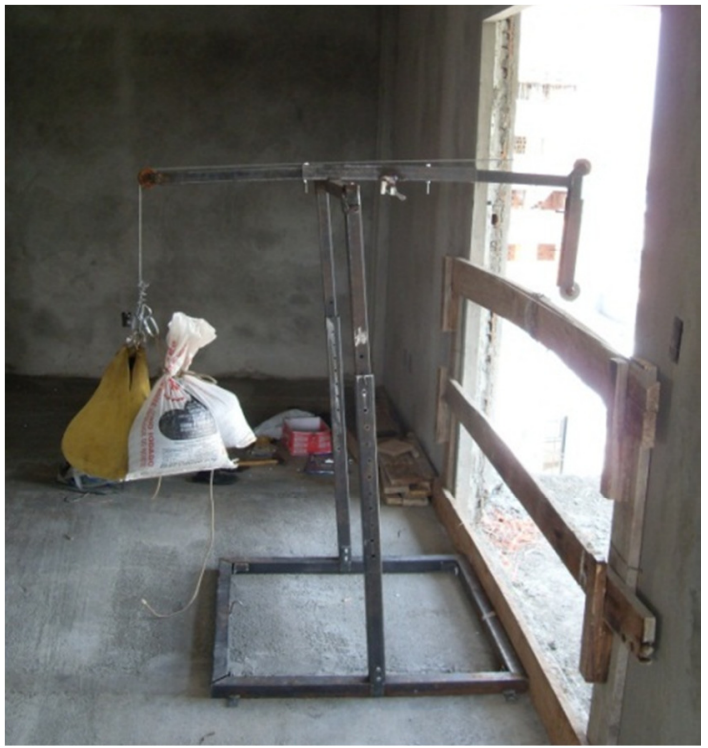

Fonte: elaboração dos autores

\subsubsection{Ensaio 08}

Guarda-corpo com guias em madeira de $2,5 \mathrm{~cm}$ de espessura e comprimento de total de $3,70 \mathrm{~m}$, com montantes metálicos fixados através parafusos com buchas metálicas na laje, e com tela protetora, na periferia da edificação.

\section{Tabela 1 - Comparativo dos guarda -corpos}

\begin{tabular}{|c|c|c|c|c|c|c|c|}
\hline \multirow{2}{*}{ Empresa } & \multirow{2}{*}{ Ensaio } & \multicolumn{2}{|c|}{ Travessão } & \multicolumn{2}{|c|}{ Montante } & \multicolumn{2}{|c|}{ Fixação do Guarda Corpo } \\
\hline & & Material & Fixação & Material & Fixação & Esquerda & Direita \\
\hline \multirow{3}{*}{ A } & 1 & $\begin{array}{l}\text { Madeira 1' } \\
\text { Pinheiro }\end{array}$ & Pregado & Escoras $7 \mathrm{~cm}$ & Pregado & $\begin{array}{c}\text { Continuação } \\
\text { do Guarda } \\
\text { Corpo }\end{array}$ & $\begin{array}{c}\text { Continuação do } \\
\text { Guarda Corpo }\end{array}$ \\
\hline & 2 & $\begin{array}{l}\text { Madeira 1' } \\
\text { Pinheiro }\end{array}$ & Pregado & $\begin{array}{l}\text { Madeira 1' - Mão } \\
\text { Francesa }\end{array}$ & Pregado & $\begin{array}{c}\text { Continuação } \\
\text { do Guarda } \\
\text { Corpo }\end{array}$ & Pilar \\
\hline & 3 & $\begin{array}{l}\text { Madeira 1' } \\
\text { Pinheiro }\end{array}$ & Pregado & \multicolumn{2}{|c|}{ Sem Montante } & \multicolumn{2}{|c|}{$\begin{array}{c}\text { Pregado em Tábuas fixadas } \\
\text { entre vigas }\end{array}$} \\
\hline B & 4 & $\begin{array}{l}\text { Madeira 1' } \\
\text { Pinheiro }\end{array}$ & Pregado & Metálicos & $\begin{array}{l}\text { Encaixe de } \\
\text { Pressão }\end{array}$ & Livre & $\begin{array}{l}\text { Continuação do } \\
\text { Guarda Corpo }\end{array}$ \\
\hline \multirow[t]{2}{*}{$\mathrm{C}$} & 5 & $\begin{array}{l}\text { Madeira 1' } \\
\text { Pinheiro }\end{array}$ & Pregado & $\begin{array}{c}\text { Barrotes de } \\
\text { madeira } 2,5^{\prime \prime} \mathrm{x} \\
2,5^{\prime \prime}\end{array}$ & $\begin{array}{l}\text { Agulhas presas } \\
\text { na Viga }\end{array}$ & Livre & Livre \\
\hline & 6 & $\begin{array}{l}\text { Madeira 1' } \\
\text { Pinheiro }\end{array}$ & Pregado & Metálicos & $\begin{array}{c}\text { Caixaria das } \\
\text { Vigas }\end{array}$ & Pilar & $\begin{array}{l}\text { Continuação do } \\
\text { Guarda Corpo }\end{array}$ \\
\hline $\mathrm{D}$ & 7 & $\begin{array}{l}\text { Madeira 1' } \\
\text { Pinheiro }\end{array}$ & Encaixado & \multicolumn{2}{|c|}{ Sem Montante } & Alvenaria & Alvenaria \\
\hline E & 8 & $\begin{array}{l}\text { Madeira 1' } \\
\text { Pinheiro }\end{array}$ & Pregado & Metálico & $\begin{array}{c}\text { Parafusado no } \\
\text { Piso }\end{array}$ & Livre & Livre \\
\hline
\end{tabular}

Fonte: elaboração dos autores

\subsubsection{Resumo dos GcR}

A tabela 1 apresenta de forma resumida as características dos sistemas guarda-corpo e rodapé ensaiados. Na mesma se identifica os materiais que compõe os sistemas, assim como a forma de fixação entre as extremidades dos mesmos. 


\subsection{Ensaios dinâmicos}

A tabela 2 resume os ensaios dinâmicos realizados. Ao contrário do ensaio estático a qual apenas dois ensaios com carregamento de $80 \mathrm{~kg}$ apresentaram deformação aceitável por norma, no ensaio dinâmico, apenas dois ensaios não resistiram a realização do ensaio de aplicação da força de $700 \mathrm{~J}$ devido o rompimento do travessão intermediário. Sendo que os outros seis ensaios não apresentaram o rompimento do travessão onde foi aplicada a força.

Tabela 2 - Resumo dos ensaios dinâmicos

\begin{tabular}{|c|c|c|c|c|}
\hline \multirow{2}{*}{ Empresa } & Ensaio & \multicolumn{2}{|c|}{ Comprimento (m) } & Resultados \\
\cline { 3 - 5 } & & $\begin{array}{c}\text { Guarda } \\
\text { Corpo }\end{array}$ & Montantes & $\begin{array}{c}\text { Teste Dinâmico } \\
\text { 700J }\end{array}$ \\
\hline \multirow{3}{*}{$\mathrm{A}$} & 1 & 5,10 & 1,70 & OK \\
\cline { 2 - 5 } & 2 & 4,80 & 2,40 & OK \\
\cline { 2 - 5 } & 3 & 3,80 & 3,80 & Rompimento \\
\hline B & 4 & 3,70 & 1,20 & OK \\
\hline \multirow{2}{*}{ C } & 5 & 1,70 & 1,10 & OK \\
\cline { 2 - 5 } & 6 & 3,80 & 1,20 & OK \\
\hline D & 7 & 2,00 & 2,00 & Rompimento \\
\hline E & 8 & 3,70 & 1,20 & OK \\
\hline
\end{tabular}

Fonte: elaboração dos autores

\subsection{Ensaios estáticos}

A tabela 3 resume os ensaios estáticos realizados. Nela é descrito o comprimento dos sistemas de GcR, o espaçamento entre os montantes, deformações admitidas por norma, e a deformação devido ao carregamento.

\section{Tabela 3 - Resumo dos ensaios estáticos}

\begin{tabular}{|c|c|c|c|c|c|c|c|}
\hline \multirow[b]{2}{*}{ Empresa } & \multirow[b]{2}{*}{ Ensaio } & \multicolumn{2}{|c|}{ Comprimento (m) } & \multirow[b]{2}{*}{$\begin{array}{l}\text { Deformação no } \\
\text { "GcR" Permitido } \\
\text { por Norma }(\mathrm{cm})\end{array}$} & \multicolumn{2}{|c|}{ Deformação $(\mathrm{cm})$} & \multirow{2}{*}{$\begin{array}{c}\text { Resultados } \\
\text { Teste } \\
\text { Estático }\end{array}$} \\
\hline & & $\begin{array}{c}\text { Guarda } \\
\text { Corpo }\end{array}$ & Montantes & & $\begin{array}{l}\text { Teste } \\
\text { Estático } \\
80 \mathrm{~kg}\end{array}$ & $\begin{array}{l}\text { Teste } \\
\text { Estático } \\
150 \mathrm{~kg}\end{array}$ & \\
\hline \multirow{3}{*}{ A } & 1 & 5,10 & 1,70 & 2,04 & 0,00 & 2,50 & $\mathrm{OK}-80 \mathrm{~kg}$ \\
\hline & 2 & 4,80 & 2,40 & 1,92 & 1,00 & 5,00 & $\mathrm{OK}-80 \mathrm{~kg}$ \\
\hline & 3 & 3,80 & 3,80 & 1,52 & \multicolumn{2}{|c|}{ Queda do Sistema } & Não Atende \\
\hline B & 4 & 3,70 & 1,20 & 1,48 & - & 4,00 & Não Atende \\
\hline \multirow{2}{*}{$\mathrm{C}$} & 5 & 1,70 & 1,10 & 0,68 & 3,00 & 6,50 & Não Atende \\
\hline & 6 & 3,80 & 1,20 & 1,52 & 7,00 & 12,00 & Não Atende \\
\hline $\mathrm{D}$ & 7 & 2,00 & 2,00 & 0,80 & 5,00 & 6,00 & Não Atende \\
\hline$E$ & 8 & 3,70 & 1,20 & 1,48 & 9,00 & 14,00 & Não Atende \\
\hline
\end{tabular}

Fonte: elaboração dos autores 
Ao realizar a análise dos ensaios estáticos sobre a deformação ocorrida, apenas o ensaio 01 e 02 apresentaram deformação aceitável por norma com o carregamento de $80 \mathrm{~kg}$. Os demais ensaios estáticos não atendem a NBR 14718 (ABNT, 2001), pois apresentam deformação maior que a permitida.

\subsection{Discussão dos Resultados}

Conforme a amostra de obras na cidade de Chapecó SC, as edificações atendem parcialmente os requisitos da NR18, apesar de todas as obras possuírem sistema de guarda-corpo e rodapé.

No entanto, ao realizar o ensaio estático com carregamento de $80 \mathrm{~kg}$, apenas $25 \%$ tiveram deformação aceita por norma, já para o carregamento de $150 \mathrm{~kg}$ todos os sistemas apresentaram deformação maior que o estabelecido por norma.

Para o ensaio dinâmico, conforme a NBR 14718 (2001), apenas 12,5 \% romperam e $12,5 \%$ apresentaram o desprendimento do sistema, sendo assim 75\% suportaram carregamento dinâmico estabelecido pela norma.

Ao comparar os resultados obtidos em obra com as seções de madeira para GcR definidas por Moreira (2004), verifica-se que, conforme o tipo de madeira e seções observadas nos ensaios, as mesmas deveriam suportar o carregamento. No entanto, o que difere entre o sistema de guarda-corpo dimensionado por Moreira (2004) com o existente em obras é o travessão superior complementar e a utilização de mão-francesa para apoio, que não foi observado nas obras ensaiadas, com exceção do ensaio 02 .

Apesar das amostras ensaiadas não terem atendido à norma, pode-se afirmar que eles atenderiam à sua função de conter os trabalhadores. Entretanto, seria necessária a reconstrução do guarda-corpo devido à perda de funcionalidade após o impacto.

\section{CONSIDERAÇÕES FINAIS}

O sistema de guarda-corpo com rodapé é um equipamento de proteção coletiva que está presente na maioria das obras de construção. No entanto muitas vezes este sistema de proteção coletiva é confeccionado de forma apenas para cumprir a NR 18, a qual é uma norma somente prescritiva, ou seja, não estabelece requisitos de desempenho.

O principal objetivo deste trabalho foi a aferição da resistência dinâmica e estática em obra dos GcR na cidade de Chapecó. Para isso foi elaborado e confeccionado um equipamento específico. A partir do equipamento foi possível realizar ensaios para comparar conforme normas vigentes, adaptadas. Entretanto, atualmente, não existe norma nacional para aferir a resistência dos mesmos, por isso foi adotado o método de ensaio dinâmico e adaptado o método de ensaio estático da NBR 14718 que trata sobre guarda-corpo definitivo para edificações. A Aenor (2004) da Espanha publicou a norma UNE-EN 13374 que trata de sistemas provisórios de guarda-corpo voltados a atividades em canteiro de obra, sendo que os métodos de ensaios contemplados por esta norma são muito semelhantes aos da norma brasileira, com algumas peculiaridades na classificação de guarda corpos e métodos de aferição, por isso não foi utilizada no presente estudo.

Ao comparar os resultados obtidos segundo a NBR 14718, obteve-se o percentual de $25 \%$ dos sistemas de GcR que resistiram ao esforço estático de $80 \mathrm{~kg}$ e $75 \%$ que suportaram o impacto do ensaio dinâmico de $700 \mathrm{~J}$

Concluindo assim, que os sistemas de guarda-corpo com rodapé analisados possuem resistência para os carregamentos prescritos, apesar de não estar de acordo com as deformações estabelecidas por norma. É importante lembrar que o GcR é confeccionado 
na maioria de suas vezes com madeiras que já sofreram carregamento. Outro aspecto importante é a forma ou modelo que o mesmo é constituído, o que influencia diretamente na dissipação dos esforços e, por consequente, na resistência do mesmo.

Quanto ao melhor modelo, o sistema de GcR do ensaio 02 teve melhor desempenho entre os demais ensaiados, principalmente por ser um sistema com mão francesa, que coincide com o modelo dimensionado por Moreira (2004).

Enfim, esse estudo é um passo inicial para provar a ineficiência dos modelos atuais de proteção contra quedas de altura. Isso abre espaço para o desenvolvimento de inovações tecnológicas nos sistemas de proteção periférica, os quais deverão ser projetados de modo a atender as necessidades e características construtivas da obra.

\section{REFERÊNCIAS}

ASOCIACIÓN ESPAÑOLA DE NORMALIZACIÓN Y CERTIFICACIÓN. UNE-EM 13374: Sistemas provisionales de protección de borde - Especificaciones del producto, métodos de ensayo. Madrid: 2004.

ASSOCIAÇÃO BRASILEIRA DE NORMAS TECNICAS. NBR 14718: Guarda-corpos para edificação. Rio de Janeiro: 2001.

ASSOCIAÇÃO BRASILEIRA DE NORMAS TÉCNICAS (ABNT). NBR-6120: Cargas para o cálculo de estruturas de edificações. Rio de Janeiro, 2000.

BRASIL, 2011. NR-9 Programa De Prevenção De Riscos Ambientais. Disponível em: http://www81.dataprev.gov.br/sislex/pinas/05/mtb/9.htm>. Acesso em: 10 de outubro de 2012

BRASIL (2013). NR-18 Condições e Meio Ambiente de Trabalho na Indústria da Construção. Disponível em: <http://www.guiatrabalhista.com.br/legislacao/nr/nr18.htm.>. Acesso em: 10 de outubro de 2013

FUNDACENTRO, Recomendações Técnicas de Procedimentos - Medidas de Proteção Contra Quedas em Alturas. São Paulo: Fundacentro, 2005.

MOREIRA, A. C. S. Proteções coletivas: modelo de dimensionamento de um sistema de guarda-corpo. São Paulo: Fundacentro, 2004.

SAMPAIO, J. C. A. PCMAT: programa de condições e meio ambiente do trabalho na indústria da construção. São Paulo: Sinduscon, 1998. 